\title{
Maturada síntese Nuno Cardoso e Platónov
}

\section{Constança Carvalho Homem}

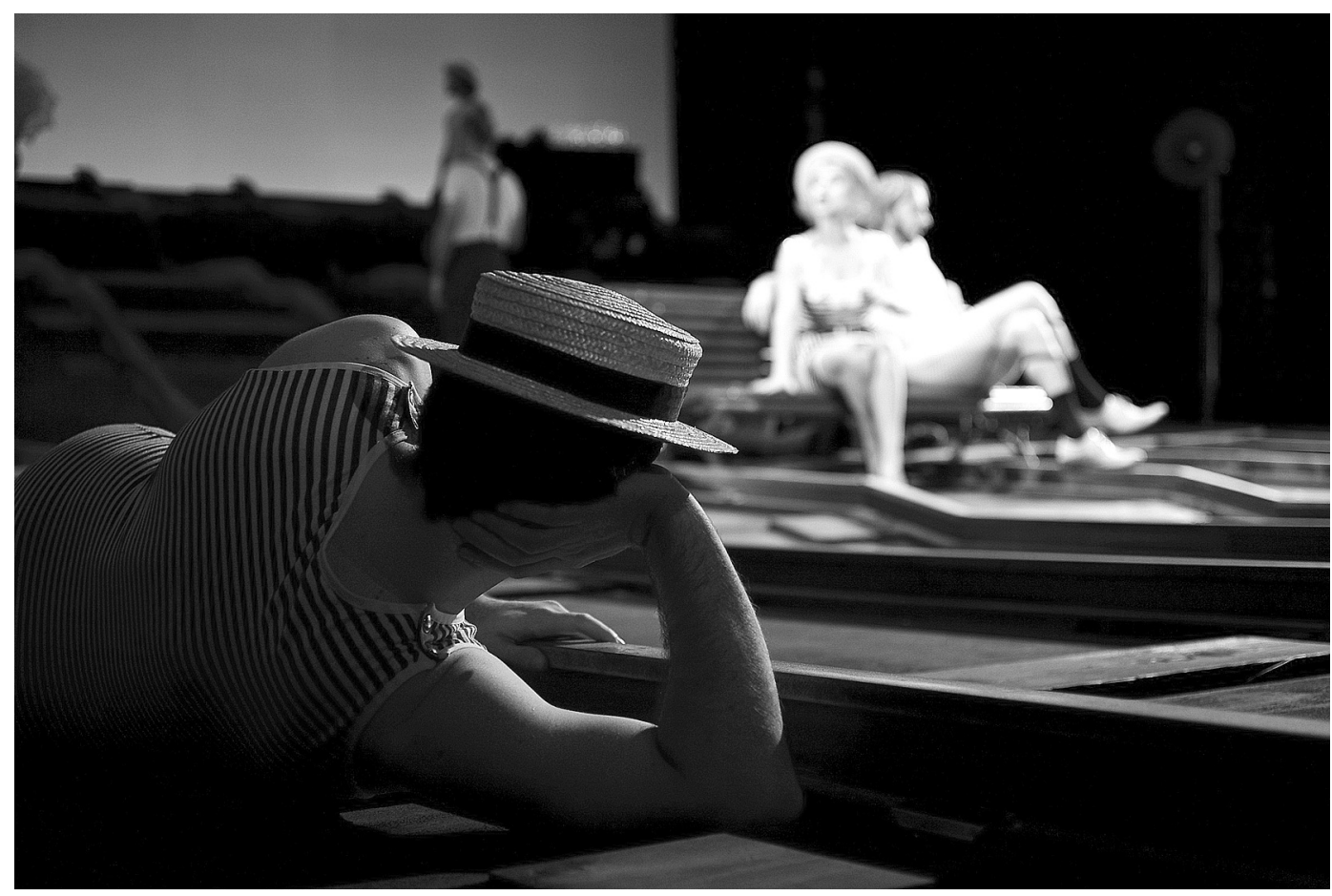

Platónov começa com um prólogo: bêbedo, trôpego, e finalmente caído por terra entre carris e cadeiras derrubadas, é Platónov quem vemos sozinho a meio caminho entre o salão e a encruzilhada. Que gesto é este, que sinal senão o da continuidade de uma linhagem de heróis improváveis?

Enquanto encenador, Nuno Cardoso tem vindo a descrever nos últimos anos um notável percurso de apropriação dos clássicos da dramaturgia europeia, dentre os quais se destacam Ibsen, Wedekind e Büchner. 2008 foi o seu ano de estreia com Tchekov, tomando como laboratório uma peça de juventude, a pérola irregular a que convencionou chamar-se Platónov. E não há dúvida de que a vertigem experimentada agora tem reminiscências de anteriores trabalhos seus - 0 despertar da Primavera, de Wedekind, Woyzeck de Büchner e até Plasticina, de Vassily Sigarev, todos eles contendo exemplos cabais de protagonistas ao arrepio da convenção, paradigmáticos já na concepção do espectáculo enquanto poliedro, com um investimento claro na consolidação de um ensemble, na produção de atmosferas de amplo recorte coreográfico e no apuro do potencial evocativo dos elementos cénicos.

Em Platónov, Nuno Cardoso chega a uma maturada sintese estilística e desenha um dos seus mais carismáticos protagonistas. É incontornável o primeiro vislumbre do cenário, uma espécie de terra de ninguém em declive onde confluem várias linhas de comboio. Incontornável a suspeita de que a todo o momento qualquer coisa possa resvalar. 0 espectáculo compagina um Platónov irreverente, abrasivo e esmagador em torno de quem gravita uma comitiva efusiva de detractores e adeptos. Dá forma também ao sedutor pouco convicto e misógino por quem as mulheres consensualmente se descabelam e, finalmente, exibe a ruína do mestre-escola, que transborda de álcool, fastio e infantilidade. Platónov é falho de ambição, mesmo que monstruoso nas suas estocadas, e tão mais rico quanto o espectáculo se alimenta da seminal dificuldade de o categorizar e responsabilizar; pouco ardiloso para pícaro, pouco perseverante para moralista e pouco obsessivo para Don Juan, é reduzido à sua sombra que Platónov merece maior simpatia.

Desde o início, tudo concorre para a iminência de um descarrilamento ou de um embate e, em simultâneo, tudo concorre para negar ou apaziguar essa iminência. 0 espectáculo acompanha os ritmos contrários latentes no texto e frustra, de forma inspirada, a expectativa de aceleração inicialmente suscitada. Surpreendentemente latino, é ao som de um Bésame mucho arrastado ao piano
Constança Carvalho Homem é bolseira da FCT (Fundação para a Ciência e a Tecnologia), doutoranda da Faculdade de Letras da Universidade do Porto. 


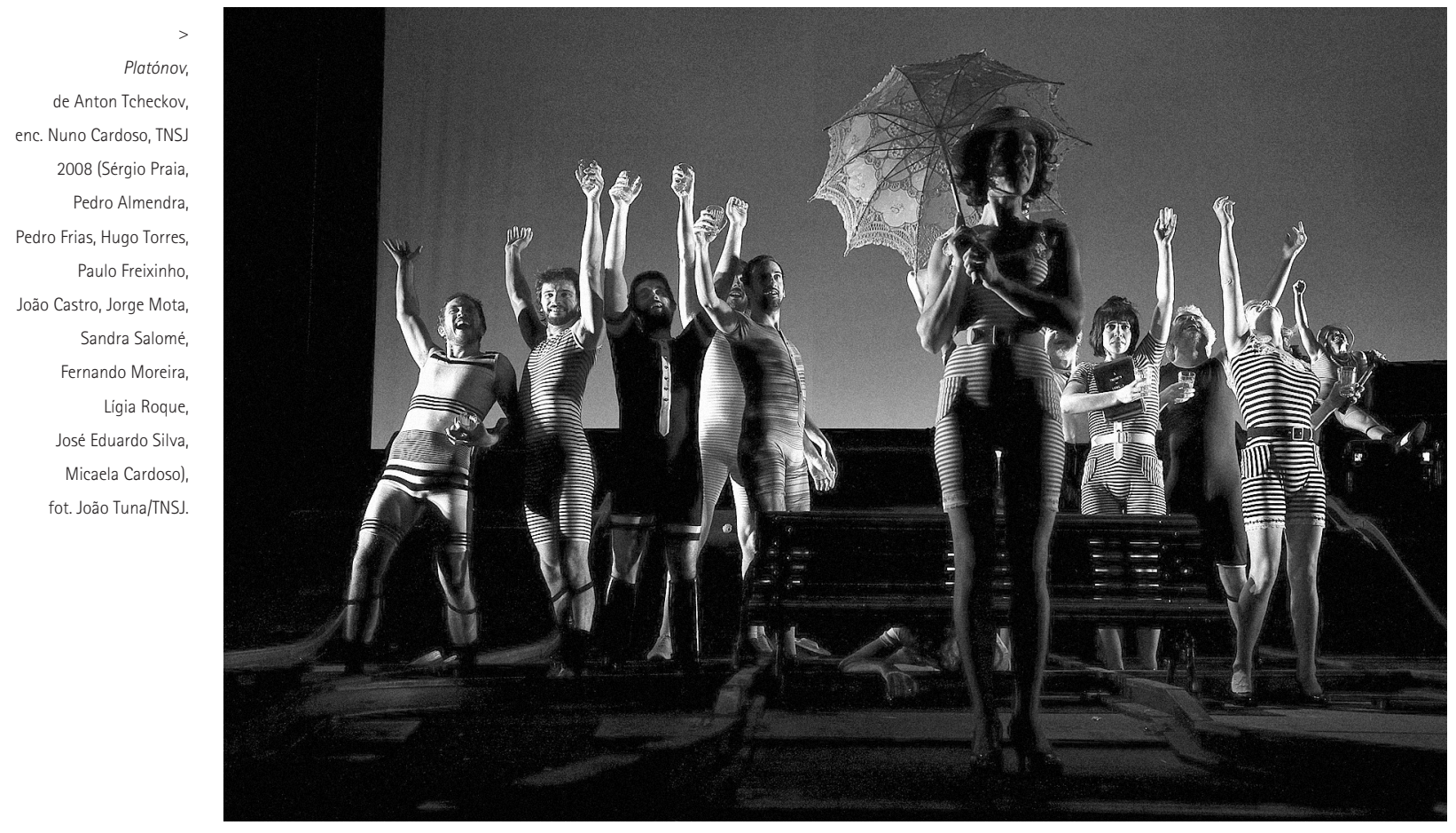

que se instala a indolência do estio e, posteriormente, é ao som de uma guitarrada que vem a insinuar-se a consumação da ilicitude. Mas também as imagens surpreendem: a certa altura, impõe-se com invulgar nitidez a afectação de uma estância balnear mediterrânica, onde os efebos jogam badmington e se passeiam em fatos de banho e chapéus de palhinha. De facto, no trabalho de Nuno Cardoso faz sentido falar-se em composição exaustiva da cena, que, neste caso, requer uma quase permanente ocupação dos actores em palco, agentes coadjuvantes de uma espécie de fórum atmosférico. Por outro lado, há uma gestão congruente das referências convocadas, um entretecer equilibrado do bolero sulamericano e do hálito de tragédia pendente que advém das semelhanças com o filme Morte em Veneza, de Visconti.

Nuno Cardoso assina um espectáculo excepcional que devolve com vigor e sageza o capítulo introdutório da mais familiar narrativa tcheckoviana: ruina, paralisia, futilidade, inconstância. "Todos vocês aqui são esquisitos!", diz Issak Abrámovitch a certa altura. E, efectivamente, talvez na plateia apeteça dizer o mesmo, de tal forma atordoa este festim da inconsequência. E esse é justamente outro dos aspectos mais entusiasmantes do espectáculo, a imensa disparidade entre a ferocidade esfuziante das personagens e tudo o que lhes está reservado, quase como se cumprissem uma rotina profiláctica de profissionalização do lazer. Há uma reserva emocional que se manifesta sob a forma de inconsciência militante e que se alcança contrariando, de um modo sustentado, a tentação de complacência para com o registo dramático. Que gesto é este, senão o da absoluta convicção da teatralidade? Em Platónov, estamos perante aquilo a que Peter Brook chamou "a explosão da alegria que não tem rumo."

0 espectáculo conta com um conjunto de intérpretes justíssimo, e de uma disponibilidade assinalável, mas devo, no entanto, sublinhar o trabalho eximio de Hugo Torres, que foi um Platónov exasperante, do mais acirrado ao mais débil. Uma palavra também para aquela que foi a associação de F. Ribeiro, José Álvaro Correia e dos Storytailorsà vertente plástica do espectáculo, pela forma decisiva com que imprimiram arrojo e eficácia às suas propostas, e à direcção de movimento de Marta Silva, um dos pilares da musculatura interpretativa do elenco.

Platónov acaba com Platónov definitivamente caído por terra. Mas porque foi, sem dúvida, um dos vértices do teatro que pudemos ver em 2008, Platónov cai onde Nuno Cardoso nos levanta. 